\title{
Effect of renal support therapy on 5-year survival in patients discharged from the intensive care unit
}

\author{
Henry Oliveros ${ }^{1,2^{*}}$ (D) and Giancarlo Buitrago ${ }^{1}$
}

\begin{abstract}
Background: Between 30 and 70\% of patients admitted to the intensive care unit (ICU) have acute kidney injury (AKI), and $10 \%$ of these patients will require renal replacement therapy (RRT). A significant number of studies have compared the mortality of patients who require RRT versus those who do not require it, finding an increase in mortality rates in the short and medium term; however, few studies have evaluated the long-term survival in a mixture of patients admitted to the ICU.

Objective: To evaluate the impact of RRT on 5-year survival in patients with AKI admitted to the ICU

Methods: Using administrative databases of insurers of the Colombian health system, a cohort of patients admitted to the ICU between 1 January 2012 and 31 December 2013 was followed until 31 December 2018. ICD-10 diagnoses, procedure codes, and prescribed medications were used to establish the frequencies of the comorbidities included in the Charlson index. Patients were followed for at least 5 years to evaluate survival and establish the adjusted risks by propensity score matching.

Results: Of the 150,230 patients admitted to the ICU, 4366 (2.9\%) required RRT in the ICU. Mortality rates for patients with RRT vs no RRT evaluated at ICU discharge, 1 year, and 5 years were $35 \%, 57.4 \%$, and $67.9 \%$ vs $7.4 \%, 17.6 \%$, and $30.1 \%$, respectively. After propensity score matching, the hazard ratio was calculated for patients who received RRT and those who did not (HR, 2.46; $95 \% \mathrm{Cl} 2.37$ to $2.56 ; p<0.001$ ), with a lower difference in years of survival for patients with RRT (mean effect in the treated) of $-1.86(95 \% \mathrm{Cl}-2.01$ to to $1.65 ; p<0.001)$.
\end{abstract}

Conclusions: The impact of acute renal failure with the consequent need for RRT in patients admitted to the ICU is reflected in a decrease of approximately one quarter in 5-year survival, regardless of the different comorbidities.

Keywords: Critical illness, Acute renal failure, Renal replacement therapy, Survival, Mortality

\section{Introduction}

The incidence of acute kidney injury (AKI) in patients admitted to the intensive care unit (ICU) varies between 30 and $70 \%$ depending on the definitions used in its classification [1-3]. Approximately $10 \%$ of these patients will require renal replacement therapy (RRT), which has

\footnotetext{
* Correspondence: h.oliverosr@javeriana.edu.co;

henry.oliveros@unisabana.edu.co

'Department of Clinical Epidemiology and Biostatistics, Pontificia Universidad Javeriana, Bogotá, Colombia

${ }^{2}$ School of Medicine, Universidad de la Sabana, Autonorte de Bogota Km 7, La Caro, Chía, Colombia
}

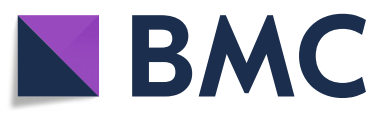

(C) The Author(s). 2020 Open Access This article is licensed under a Creative Commons Attribution 4.0 International License, which permits use, sharing, adaptation, distribution and reproduction in any medium or format, as long as you give appropriate credit to the original author(s) and the source, provide a link to the Creative Commons licence, and indicate if changes were made. The images or other third party material in this article are included in the article's Creative Commons licence, unless indicated otherwise in a credit line to the material. If material is not included in the article's Creative Commons licence and your intended use is not permitted by statutory regulation or exceeds the permitted use, you will need to obtain permission directly from the copyright holder. To view a copy of this licence, visit http://creativecommons.org/licenses/by/4.0/ The Creative Commons Public Domain Dedication waiver (http://creativecommons.org/publicdomain/zero/1.0/) applies to the data made available in this article, unless otherwise stated in a credit line to the data.

a considerable impact on the use of health resources, with costs between $\$ 11,016$ and $\$ 42,077$ USD per patient $[4,5]$. Mortality also varies widely, ranging from 15 to $60 \%$ depending on the associated diseases [6, 7]. Approximately $30 \%$ of patients discharged from the ICU that required RRT will remain in the most advanced stage of chronic kidney disease (CKD-5) [7-9], which could be related to a lower long-term survival [10-12]. Different studies have established risk factors at the individual level that determine prognosis. These factors have been first grouped into factors that determine the renal 
reserve with which a patient enters the ICU, such as age, sex, and comorbidities (hypertension, diabetes) [3, 13, 14]. Second are the conditions for which patients are admitted to the ICU, such as shock states, sepsis, heart failure, and cancer [15-17]. Third, factors to which the patient is exposed during the ICU stay, such as antibiotic therapy, contrast media, vasopressors, or fluid resuscitation, and all these interact to determine the severity of renal injury [18].

Although risk factors have been identified in multiple studies, few have monitored the long-term renal function outcomes in patients discharged from the ICU who presented with AKI requiring dialysis. Determining the individual modifiable factors that could change the course of kidney disease has been the main motivation of studies that have addressed this problem.

Our objective was to determine the 5-year survival of patients admitted to the ICU who required RRT compared to patients who did not require RRT to determine the effect of therapy on survival.

\section{Methods}

\section{Study type of and data sources}

A retrospective cohort study was conducted with administrative data obtained from the per-capita payment unit (UPC) sufficiency database of the Integrated Social Protection Information System (SISPRO) of the Colombian Ministry of Health. This database contains event reports of the services provided by insurance companies (Health Promoter Enterprises [EPS]) of the Colombian health system, which covered 22.5 million Colombians in 2012 (48\% of the population). The database is highly standardized and contains the codes of the services provided (CUPS), the date the service was provided, age, sex, insurance company, municipality, ICD-10 code, and cost of care. Information on mortality, date of death, and diagnoses associated with the cause of death was obtained from death certificates.

\section{Population}

The study population consisted of Colombian patients older than 18 years who were first admitted to the ICU between 1 January 2012 and 31 December 2013. Patients were identified by procedure codes related to ICU admission (see Annex 1). Patients who in the previous year were admitted to the ICU or who required renal support therapy in any hemodialysis or peritoneal dialysis modalities were excluded.

\section{Study variables}

The main exposure was the requirement for dialysis therapy, and the main outcome was 5-year survival with administrative cutoff of 31 December 2018. Additionally, mortality was determined at ICU discharge and after 1 year and the continued requirement for renal support after 3 months.

In all patients, the demographic characteristics of age, sex, region of care, and the 16 comorbidities included in the Charlson index, in addition to hypertension, were identified, and last, the condition for which they were admitted to the ICU, such as trauma, heart failure, or sepsis. This information was obtained through the construction of algorithms based on the CUPS procedure codes, ICD-10 diagnoses, and records of administered medications (Annex 1).

\section{Statistical analysis}

First, a descriptive analysis was performed to determine the baseline clinical and demographic characteristics of the groups according to exposure to RRT or not, obtaining the calculation of standardized differences. Second, patients were followed from admission to death for at least 5 years, with administrative cutoff of 31 December 2018. The Kaplan-Meier method was used to obtain the survival curves and to estimate the cumulative mortality at three time points: during ICU stay, between ICU admission and the first year, and between ICU admission and at least 5 years. The hazard ratio (HR) was calculated, both crude and adjusted for age, sex, comorbidities, condition for ICU admission, and region of the country using Cox's proportional hazards regression. The proportional hazards assumption was verified graphically using $\log (-\log$ (survival probability)) plots and was found to be appropriate. To reduce possible selection biases due to the lack of randomization and control of confounding variables, matching techniques were performed by determining the propensity index according to the recommendations of Austin [19, 20]. Last, the HRs for the matched groups were recalculated according to the recommendation of Cole and Hernán [21] and confidence intervals using bootstrapping.

The propensity score was obtained from a logistic regression model including the following variables: age, sex, geographical location of the ICU, variables contained in the Charlson index [22], presence of hypertension, condition for ICU admission such as trauma, sepsis or heart failure, and use of contrast media. Subsequently, the matching algorithm was applied, with which the mean effect of RRT was calculated in terms of time to death. The different matching methods were compared to obtain the best balance in the baseline characteristics. The methods used were as follows: nearest-neighbor with ratios of 1:1, 1:5, and 1:10; caliper of 0.05 and 0.001; and Kernel. The nearest neighbor method seeks to match the treated and untreated subjects, trying to make the paired scores as close as possible, while the caliper method establishes a range of closeness based on a measurement in terms of the standard deviation of the 
propensity, usually a value of 0.05 standard deviations $[23,24]$. The criterion used to evaluate the best balance of the baseline characteristics between the groups was to obtain standardized differences less than 0.1 and the lowest value in the index by Rubin and Thomas [25]. Next, the 95\% confidence intervals were calculated, and robust standard errors were estimated.

\section{Ethics approval}

Patient records were anonymized, and this study was approved for exemption from informed consent rules by the Ethics Review Board of Pontificia Universidad Javeriana, Bogota, Colombia.

\section{Results}

\section{Descriptive analysis}

A total of 167,991 patients who were admitted to ICUs in Colombia were identified during the study period, and 17,761 patients with prior admission to the ICU or previous RRT were excluded, with 150,230 patients remaining. Of these, $4366(2.9 \%)$ patients required RRT during ICU stay, as shown in Fig. 1.

The overall mortality at discharge from the ICU was $8.3 \%$, at 1 year was $18.8 \%$, and at 5 years was $31.2 \%$. The two regions that served more than half of the patients were Bogota Central region of the country. Table 1 shows the standardized differences in the baseline characteristics; the group of patients who required RRT had an older age, 67 years $( \pm 15.6)$ vs 60.5 years $( \pm 12.2)$, a higher proportion of diabetic patients (33.5\% vs $18.7 \%$ ), and a higher frequency of patients with sepsis $(21.6 \%$ vs $8.2 \%)$. Mortality in patients requiring RRT vs. no RRT evaluated at three time points-at discharge from the ICU, at 1 year, and at 5 years-was $35 \%, 57.4 \%$, and $67.9 \%$ vs. $7.4 \%, 17.6 \%$, and $30.1 \%$, respectively.

The median overall survival time was 2.6 years $(95 \%$ CI 2.5 to 2.7) for patients requiring RRT and 5.3 years (95\% CI 5.22 to 5.25 ) for patients not requiring RRT.

The characteristics of the groups of patients requiring RRT and not requiring RRT after propensity score matching are presented in Table 2.

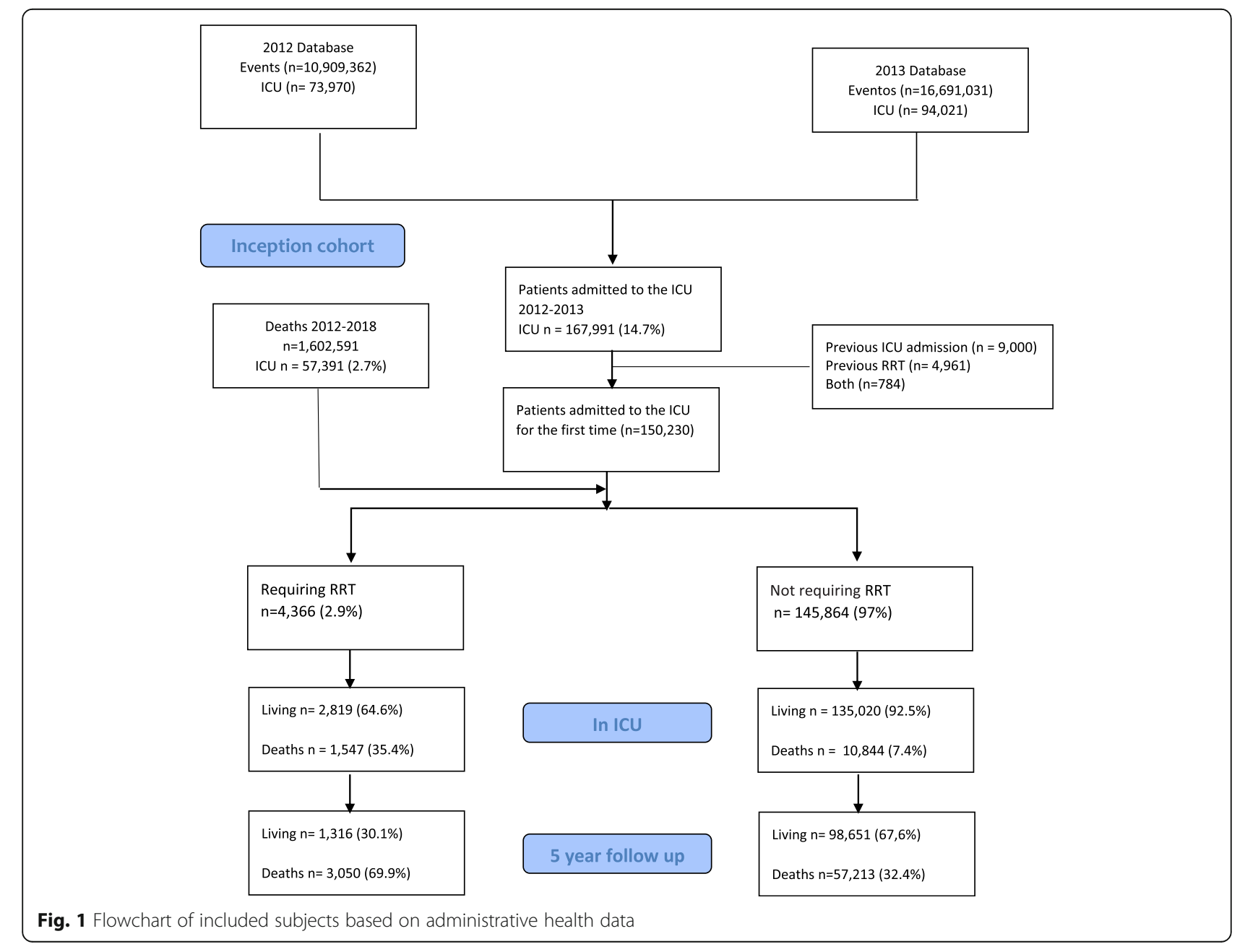


Table 1 General characteristics of patients admitted to the ICU from 2011 to 2012 in 180 ICUs in Colombia

\begin{tabular}{|c|c|c|c|c|c|}
\hline \multirow[t]{3}{*}{ Baseline characteristics } & \multirow{3}{*}{$\begin{array}{l}\text { Full sample } \\
\boldsymbol{n}=150,230\end{array}$} & \multicolumn{2}{|c|}{ Exposure status } & \multirow{3}{*}{$\begin{array}{l}\text { Standardized } \\
\text { differences }\end{array}$} & \multirow{3}{*}{$\boldsymbol{P}$ value } \\
\hline & & \multirow{2}{*}{$\begin{array}{l}\text { RRT } \\
\boldsymbol{n}=4,366\end{array}$} & \multirow{2}{*}{$\begin{array}{l}\text { No RRT } \\
\boldsymbol{n}=145,864\end{array}$} & & \\
\hline & & & & & \\
\hline Age mean (SD) & $60.7(19.2)$ & 67 (15.6) & $60.5(12.3)$ & 0.373 & 0.001 \\
\hline \multicolumn{6}{|l|}{ Age, $n(\%)$} \\
\hline $18-50$ & $39,821(26.5)$ & $587(13.4)$ & $39,234(26.9)$ & -0.340 & 0.001 \\
\hline $51-60$ & $22,677(15.1)$ & $567(13)$ & $22,110(15.1)$ & -0.062 & 0.001 \\
\hline $61-70$ & $29,727(19.8)$ & $964(22.1)$ & $28,763(19.7)$ & 0.058 & 0.001 \\
\hline $61-70$ & $32,225(21.5)$ & $1273(29.2)$ & $30,952(21.2)$ & 0.184 & 0.001 \\
\hline $71-80$ & $21,951(14.6)$ & $886(20.3)$ & $21,065(14.4)$ & 0.155 & 0.001 \\
\hline $81-90$ & $3784(2.5)$ & $88(2.0)$ & $3696(2.5)$ & -0.035 & 0.031 \\
\hline $91-100$ & $45(0.03)$ & $1(0.02)$ & $44(0.03)$ & -0.004 & 0.785 \\
\hline \multicolumn{6}{|l|}{ Region, $n(\%)$} \\
\hline Atlantic & $19,354(12.8)$ & $720(16.4)$ & $18,634(12.8)$ & -0.105 & \\
\hline Bogota & $45,615(30.4)$ & $1,072(24.6)$ & $44,543(30.5)$ & -0.134 & 0.001 \\
\hline Central & $34,241(22.8)$ & $1060(24.3)$ & $33,181(22.8)$ & 0.036 & 0.018 \\
\hline Eastern & $19,789(13.2)$ & $639(14.6)$ & $19,150(13.1)$ & 0.044 & 0.004 \\
\hline Pacific & $30,303(20.1)$ & 855 (19.6) & $29,448(20.2)$ & -0.015 & 0.326 \\
\hline Other & $928(0.62)$ & $20(0.46)$ & $908(0.62)$ & -0.022 & 0.172 \\
\hline Female sex, $n(\%)$ & $75,566(51)$ & $1786(40,9)$ & $74,789(51.2)$ & 0.209 & 0.001 \\
\hline \multicolumn{6}{|l|}{ Admission to ICU, $n(\%)$} \\
\hline Congestive heart failure & $10,150(6.8)$ & $433(9.9)$ & $9717(6.7)$ & 0.118 & 0.001 \\
\hline Trauma & $6448(4,3)$ & $182(4,2)$ & $6266(4.3)$ & -0.006 & 0.68 \\
\hline Sepsis & $12,854(8.6)$ & $941(21.6)$ & $11,913(8.2)$ & 0.383 & 0.001 \\
\hline \multicolumn{6}{|l|}{ Comorbidities, $n$ (\%) } \\
\hline Myocardial infarction & $11,983(8)$ & $276(6.3)$ & $11,707(8)$ & -0.066 & 0.001 \\
\hline Congestive heart failure & $12,020(8)$ & $523(11.9)$ & $11,497(7.9)$ & 0.137 & 0.001 \\
\hline Peripheral vascular disease & $4977(3.1)$ & $183(4.2)$ & $4794(3.4)$ & 0.048 & 0.001 \\
\hline Cerebrovascular disease & $8043(5.4)$ & $281(6.4)$ & $7762(5.3)$ & 0.047 & 0.001 \\
\hline Dementia & $12,874(8.6)$ & $334(7.7)$ & $12,540(8.6)$ & -0.035 & 0.028 \\
\hline Chronic pulmonary disease & $26,218(17.5)$ & $882(20.2)$ & $25,336(17.4)$ & 0.073 hg & 0.001 \\
\hline Connective tissue disease & $5278(3.5)$ & $211(4.8)$ & $5067(3.5)$ & 0.068 & 0.001 \\
\hline Peptic ulcer disease & $17,101(11.4)$ & $555(12.7)$ & $16,546(11.3)$ & 0.042 & 0.05 \\
\hline Mild liver disease & $1290(0.9)$ & $68(1.6)$ & $1222(0.84)$ & 0.066 & 0.001 \\
\hline Diabetes mellitus & $28801(19.2)$ & $1463(33.5)$ & $27,338(18.7)$ & 0.341 & 0.001 \\
\hline Metastasis solid tumor & $4141(2.7)$ & $119(2.7)$ & $4022(2.8)$ & -0.002 & 0.9 \\
\hline AIDS & $682(0.5)$ & $16(0.4)$ & $666(0.5)$ & -0.014 & 0.38 \\
\hline Any tumour & $1004(0.7)$ & $38(0.9)$ & $966(0.7)$ & 0.024 & 0.09 \\
\hline Hypertension & $78,898(52.2)$ & $2904(66.5)$ & $75,994(52.1)$ & 0.297 & 0.001 \\
\hline \multicolumn{6}{|l|}{ Mortality, $n(\%)$} \\
\hline Discharge from ICU & $12,391(8.3)$ & $1547(35)$ & $10,844(7.4)$ & & 0.001 \\
\hline 1 year & $28,243(18.8)$ & 2507 (57.4) & $25,736(17.6)$ & & 0.001 \\
\hline 5 year & $46,809(31.2)$ & $2966(67.9)$ & $43,843(30.1)$ & & 0.001 \\
\hline ICU stay, mean (SD) & $7.1(95)$ & $9.9(275)$ & $7.0(96)$ & & 0.001 \\
\hline Follow-up time, years & $4.5(2.4)$ & $2.3(2.7)$ & $4.6(2.4)$ & & 0.001 \\
\hline
\end{tabular}

To calculate $P$ values, the chi-squared test was used for categorical variables and Student's $t$ test for continuous variables 
Table 2 Baseline characteristics in each of the groups after matching

\begin{tabular}{|c|c|c|c|c|}
\hline Variable & $\mathrm{RRT} \boldsymbol{n}=4366$ & No RRT $\boldsymbol{n}=145,864$ & Standardized differences & $\boldsymbol{P}$ value \\
\hline \multicolumn{5}{|l|}{ Age, (\%) } \\
\hline $51-60$ & 12.9 & 12.6 & 1.0 & 0.631 \\
\hline $61-70$ & 22.1 & 22.1 & 0.1 & 0.979 \\
\hline $61-70$ & 29.2 & 29.2 & -0.1 & 0.962 \\
\hline $71-80$ & 20.3 & 21.0 & -1.9 & 0.398 \\
\hline $81-90$ & 2.0 & 2.2 & -0.9 & 0.653 \\
\hline $91-100$ & 0.02 & 0.05 & -1.4 & 0.564 \\
\hline \multicolumn{5}{|l|}{ Region, (\%) } \\
\hline Bogota & 24.5 & 24.2 & 0.8 & 0.709 \\
\hline Central & 24.3 & 24.7 & -0.9 & 0.672 \\
\hline Eastern & 14.6 & 14.5 & 0.4 & 0.856 \\
\hline Pacific & 19.6 & 19.9 & -1.0 & 0.648 \\
\hline Other & 0.46 & 0.32 & 1.9 & 0.303 \\
\hline Female sex, (\%) & 59.1 & 58.8 & 0.6 & 0.761 \\
\hline \multicolumn{5}{|l|}{ Admission to ICU $n$ (\%) } \\
\hline Congestive heart failure & 9.9 & 9.9 & -0.1 & 0.971 \\
\hline Trauma & 4.2 & 4.2 & 0.0 & 1.000 \\
\hline Sepsis & 21.5 & 21.7 & -0.3 & 0.897 \\
\hline \multicolumn{5}{|l|}{ Comorbidities, (\%) } \\
\hline Myocardial infarction & 6.3 & 5.6 & 2.9 & 0.135 \\
\hline Congestive heart failure & 11.9 & 11.7 & 0.9 & 0.691 \\
\hline Peripheral vascular disease & 4.2 & 3.9 & 1.7 & 0.446 \\
\hline Cerebrovascular disease & 6.4 & 5.5 & 4.1 & 0.058 \\
\hline Dementia & 7.7 & 7.8 & -0.4 & 0.841 \\
\hline Chronic pulmonary disease & 20.2 & 19.5 & 1.9 & 0.391 \\
\hline Connective tissue disease & 4.8 & 4.9 & -0.8 & 0.729 \\
\hline Peptic ulcer disease & 12.7 & 11.6 & 3.5 & 0.109 \\
\hline Mild liver disease & 1.6 & 1.2 & 2.9 & 0.202 \\
\hline Diabetes mellitus & 33.5 & 32.8 & 1.6 & 0.481 \\
\hline Metastasis solid tumor & 2.7 & 2.5 & 1.4 & 0.502 \\
\hline AIDS & 0.36 & 0.23 & 2.1 & 0.239 \\
\hline Any tumor & 0.87 & 0.96 & -1.1 & 0.653 \\
\hline Hypertension & 66.5 & 65.6 & 1.9 & 0.354 \\
\hline Renal disease & 5.7 & 5.4 & 1.5 & 0.574 \\
\hline
\end{tabular}

\section{Impact of RRT on long-term survival}

After matching using different algorithms as shown in Table 3, and after evaluating the common support zone (Figure 1S), the differences in the mean effect between patients who received RRT and those who did not receive it were obtained. The best balance of the baseline characteristics was obtained by the caliper method with a maximum distance of 0.01 SD (RRT years, - 1.86; 95\% CI -2.01 to $-1.65 ; p<0.001)$.

Figure 2 shows the unadjusted Kaplan-Meier survival curves of patients requiring RRT and not requiring RRT with a minimum follow-up of 5 years after admission to the ICU. Differences in survival were established early in the first days during hospitalization (Log-rank test, $p<0.001$ ).

\section{Five-year mortality risk of RRT and associated factors}

The 5-year HR for exposure to RRT was calculated, including the crude HR, HR adjusted for the baseline characteristics for the two groups, and HR adjusted by caliper matching of $0.01 \mathrm{SD}$, respectively: crude $\mathrm{HR}$, 3.40; $95 \%$ CI 3.27 to $3.52 ; p<0.001$; adjusted HR, 2.7; 95\% CI 2.6 to 2.8; $p<0.001$; and adjusted HR with 
Table 3 Differences in mean effect on treated patients in terms of survival years according to the matching algorithm

\begin{tabular}{|c|c|c|c|c|c|c|c|}
\hline Matching method & Difference RRT years & 95\% Cl Bootstrap & $B^{*}$ & Treated RRT & Controls no RRT & Mortality HR (95\% Cl) & Difference 5-year mortality \% \\
\hline \multicolumn{8}{|l|}{ Nearest neighbor } \\
\hline 1 & -1.85 & $(-2.03$ to -1.64$)$ & 9.2 & 4366 & 2302 & 2.27 (2.0 to 2.5$)$ & 27.5 (24.9 to 30.2$)$ \\
\hline 5 & -1.78 & $(-2.00$ to -1.62$)$ & 10.4 & 4366 & 10,812 & $2.3(2.2$ to 2.5$)$ & 27.5 (23.9 to 31.2$)$ \\
\hline 10 & -1.76 & $(-1.98$ to -1.64$)$ & 11.4 & 4366 & 20,011 & $2.3(2.2$ to 2.4$)$ & 27.6 (23.7 to 31.5$)$ \\
\hline \multicolumn{8}{|c|}{ Maximum caliper distance } \\
\hline 0.01 & -1.86 & $(-2.01$ to -1.65$)$ & 6.1 & 4354 & 2,301 & 2.46 (2.37 to 2.56$)$ & 24.5 (20.7 to 28.3$)$ \\
\hline 0.05 & -2.15 & $(-2.02$ to -1.64$)$ & 43.9 & 4366 & 2283 & 2.31 (2.06 to 2.59$)$ & $26.3(22.5$ to 30.1$)$ \\
\hline Kernel & -2.13 & $(-2.01$ to -1.66$)$ & 41.7 & 4366 & 145,864 & 2.88 (2.77 to 2.99$)$ & 26.2 (22.8 to 29.5$)$ \\
\hline
\end{tabular}

*if $B>25 \%$

matching, 2.46; 95\% CI 2.37 to $2.56 ; p<0.001$ (Fig. 3 and Table 3S). The variable that presented the greatest association with mortality was age above 80 years, with an increasing increase for each decade after 50 years (Figure 2S and Table 4S).

Five-year HR for exposure to RRT: crude, adjusted by the Cox model and adjusted with propensity score matching.

\section{Development of CKD and dependence on dialysis therapy} Of the 4366 (2.91\%) patients who required RRT, 621 (14.32\%) still required RRT by dialysis after 90 days (Table 4 and Figure 3S). The mortality of patients who remained on dialysis vs. those who did not require continuous RRT (CRRT) was $67.88 \%$ vs. $32.98 \%$, respectively. However, when the analysis was performed after 90 days and mortality was compared between the subgroup requiring CRRT and patients who did not receive RRT, mortality was $57.33 \%$ vs. $32.06 \%$, respectively. After adjusting for confounding by propensity score matching, we compare the mortality in patients that remained with CRRT at 90 days, with patients that did not require RRT due to recovered renal function, we obtained a hazard ratio of 2.4 and a 5 -year mortality of $57 \%$ vs. $33 \%$ for CRRT and RRT respectively.

\section{Discussion}

Using propensity score matching methods, the present study found an HR of 2.46 (95\% CI 2.37 to 2.56; $p<$ $0.001)$ with a decrease in 5-year survival of - $1.86(95 \%$ CI -2.01 to $-1.65 ; p<0.001)$ in adult patients who received RRT during their stay in the ICU in Colombia. This result highlights the impact on the Colombian population caused by AKI and its treatment. Several studies have estimated the risk of AKI and RRT in the ICU $[9,12,18,26]$; however, to our knowledge, there are no studies that have estimated the impact on 5-year survival.

This percentage difference in survival is $24.5 \%$ (20.7 to 28.3) lower in patients receiving RRT, which gives an idea of the impact of this condition. There are several studies that do not support this difference. Recently, Abudayyeh et al. [26] studied the impact of RRT in 465

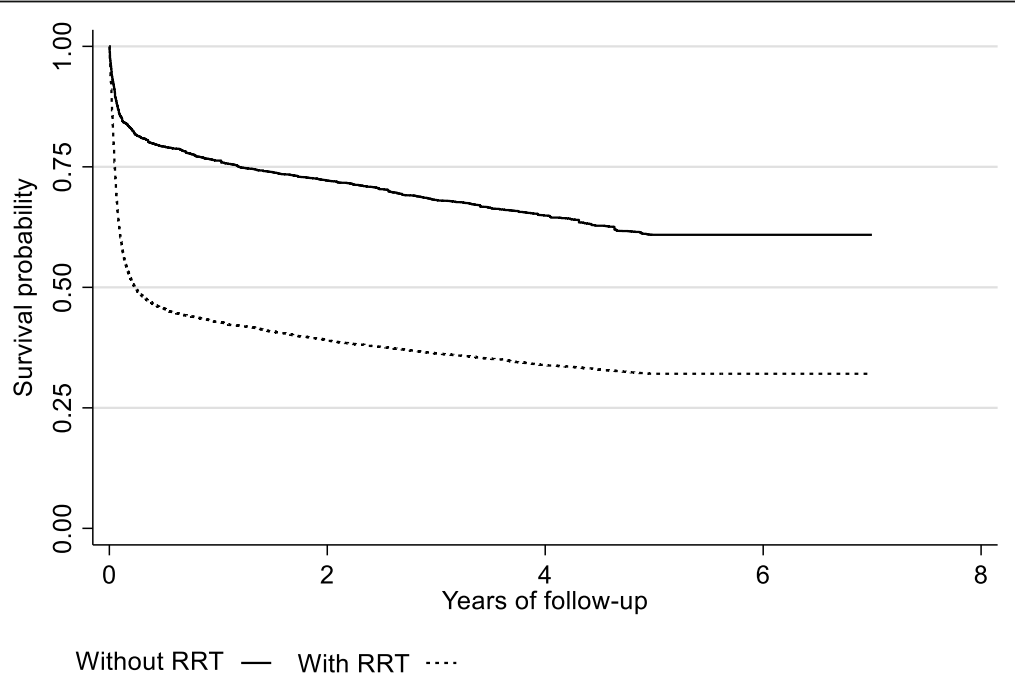

Fig. 2 Five-year survival curves of patients requiring RRT and not requiring RRT. Numbers of subjects 150,230, there were 50,263 failures with a rate of 7.4 events per 100 patient-years 


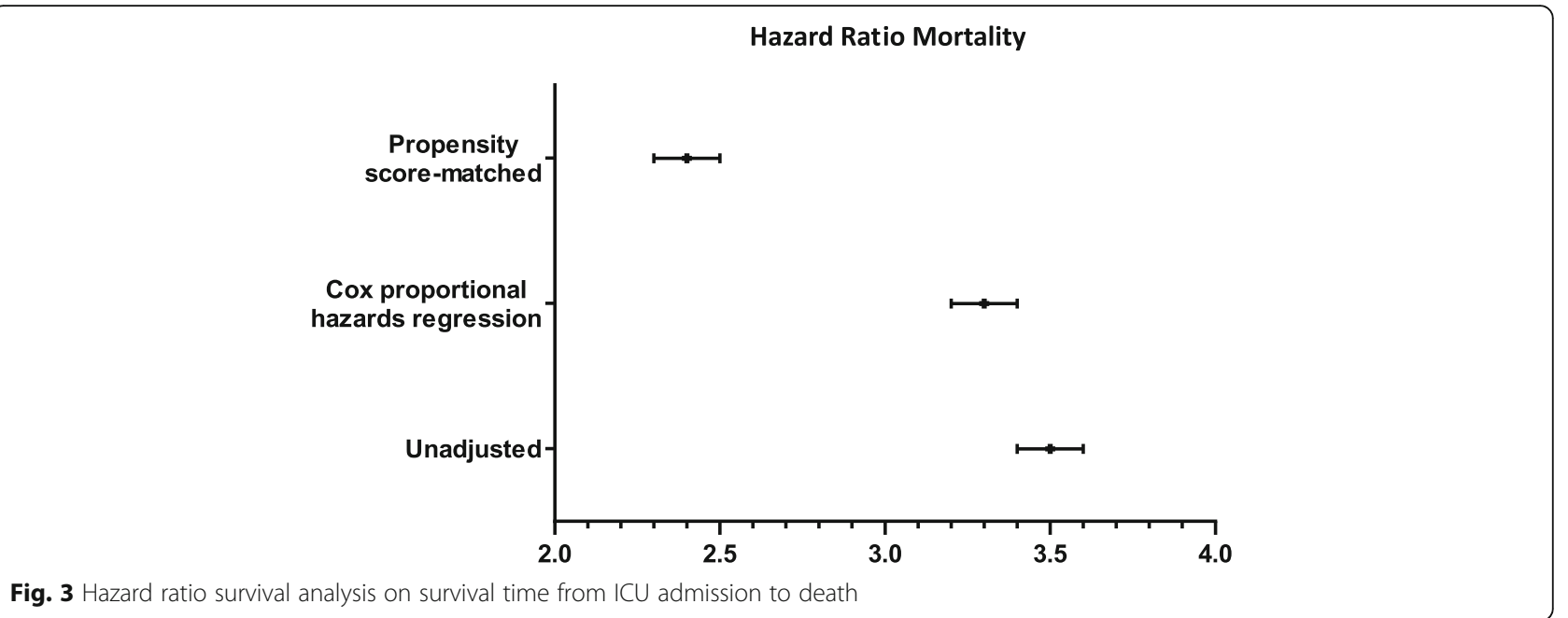

cancer patients admitted to the ICU; mortality at hospital discharge compared with patients who did not receive RRT adjusted by the propensity score showed no differences in the risk of mortality at hospital discharge. Similar findings were observed in patients older than 70 years who required dialysis in the ICU, with no differences in mortality at ICU discharge compared with patients who did not require RRT [27]. While Lebiedz's study concludes that in 524 critically ill patients with mechanical ventilation requirements, pre-existing CKD has a marked impact on the occurrence of acute renal failure, 30 days and 1-year mortality [28].

The findings of our study are supported on the basis of having obtained large cohort of patients admitted to the ICU that represents approximately $48 \%$ of the population served in Colombia in approximately 300 ICUs. Additionally, algorithms were used that covered different dimensions in the identification of the variables. Moreover, in addition to the ICD-10 codes, medical procedure codes and the medications received by the patients were included for the identification of the comorbidities,

Table 4 Adjusted odds ratio for stay on hemodialysis after 90 days in patients with acute kidney injury

\begin{tabular}{lll}
\hline Characteristic & Odds ratio $(95 \%$ Cl) & $P$ value \\
\hline Age, mean (SD) & $0.97(0.96$ to 0.98$)$ & 0.001 \\
Female sex, $n$ (\%) & $1.40(1.17$ to 1.69$)$ & 0.001 \\
Diabetes mellitus, $n$ (\%) & $1.57(1.30$ to 1.90$)$ & 0.001 \\
Hypertension, $n$ (\%) & $1.71(1.37$ to 2.15$)$ & 0.001 \\
CKD, $n$ (\%) & $1.86(1.37$ to 2.53$)$ & 0.001 \\
CPD, $n$ (\%) & $0.62(0.49$ to 0.80$)$ & 0.001 \\
Sepsis, $n(\%)$ & $0.46(0.35$ to 0.59$)$ & 0.001 \\
Trauma, $n$ (\%) & $0.51(0.34$ to 0.72$)$ & 0.016 \\
\hline
\end{tabular}

$P$ value corresponds to the association of the independent variable with the permanence in dialysis at 90 days

$C K D$ chronic kidney disease, CPD chronic pulmonary disease thus including different dimensions which, as argued by Schneeweiss et al., lead to better control of unobserved confounding variables [29]. The comparison of different matching methods allowed us to choose the algorithm with which the best balance of baseline characteristics between the groups was obtained and thus calculate less biased estimates and with greater accuracy $[19,20,30$, 31]. Nevertheless, we recognize the limitations of not having information on severity scores for the population of patients admitted to the ICU, which would provide us with information about the acute condition of the disease and thus allow us to adjust for severity at the time of ICU admission.

Taking into account a large number of comorbidities and the diagnoses for which the patient were admitted to the ICU, in addition to variables that reflect differences in access and opportunity for health care between the different municipalities of Colombia, allowed us to adjust for a large number of confounding variables [22, 32] and thus obtain less biased estimates, as evidenced in the comparison of the crude and adjusted estimates for the HRs, differences in mean survival times and 5year mortality percentages (Table 4).

The limitations of the present study are related to the data source, as the data were obtained from administrative databases which ordinarily do not include variables such as biomarkers and severity scores. Some studies that have included biomarkers do not report a discriminatory capacity for the prediction of kidney injury outcomes. Recently, Chen et al. [33] and Malhotra et al. [34] developed predictive models based mainly on clinical characteristics such as sex, age, hypertension, diabetes, coronary heart disease, heart failure, sepsis, mechanical ventilation, total bilirubin, hypoalbuminemia, emergency surgery, cancer, chronic kidney disease, and exposure to nephrotoxic agents, finding an adequate discriminatory capacity (area under the curve of 0.81 ). In our study, in addition to the 
comorbidities included in the Charlson index, variables such as diagnosis of sepsis, heart failure or trauma at admission to the ICU, and the use of contrast media during ICU stay were considered.

\section{Conclusions}

The impact of acute renal failure with the consequent requirement for RRT in patients admitted to the ICU is reflected in a decrease of approximately one quarter in 5 -year survival, regardless of the different comorbidities. Therefore, attention should be directed towards preventing ICU patients from developing to acute renal failure to improve their prognosis. In the present study, it was observed that dialysis therapy in the ICU alone is not the only factor determining worse outcomes.

\section{Supplementary information}

Supplementary information accompanies this paper at https://doi.org/10. 1186/s40560-020-00481-0.

Additional file 1: Annex 1. ICD-10 codes to define Charlson index COmorbidities; Table 3S. Survival analysis of survival time from ICU admission to death. Mortality hazard ratio ; Table $\mathbf{4 S}$. Predictors of mortality by Cox regression model among propensity score-matched patients with RRT compared with those without; Figure 1S. Probability distributions according to the propensity score for patients treated with RRT and for patients not treated with RRT logit; Figure 2S. Mortality hazard ratio for each variable. CKD: chronical kidney disease; Figure 35. Causal diagrams representing the potential mediation of co-morbidities, ICU interventions, in the association between renal failure requiring dialysis and renal replacement therapy and survival.

\section{Abbreviations}

AKI: Acute kidney injury; RRT: Renal replacement therapy; Cl: Confidence interval; CIAKI: Contrast-induced acute kidney injury; CKD: Chronic kidney disease; CRRT: Chronic renal replacement therapy; ICD-10: International Classification of Diseases, 10th Revision, Clinical Modification; ICU: Intensive care unit; PS: Propensity score; OR: Odds ratio; RR: Risk ratio; SAH: Systemic arterial hypertension; Sdif: Standardized difference

\section{Acknowledgements}

Not applicable.

\section{Authors' contributions}

All authors contributed to the design of the study. $\mathrm{HO}$ and $\mathrm{GB}$ take responsibility for the integrity of the data and accuracy of the data analysis Both wrote the manuscript and revised the manuscript. Both authors read and approved the final manuscript.

\section{Funding}

This study was founded by the University of La Sabana.

\section{Availability of data and materials}

The Information System (SISPRO) of the Colombian Ministry of Health provided the anonymized databases. The refined bases and the code used in the creation of the algorithms were made in STATA MP V.16 and are available to anyone who requests it.

\section{Ethics approval and consent to participate}

Patient records were anonymized, and this study was approved for exemption from informed consent rules by the Ethics Review Board of Pontificia Universidad Javeriana, Bogota Colombia.

\section{Competing interests}

The authors of this manuscript have no competing interests directly related to the manuscript's content.

Received: 29 June 2020 Accepted: 10 August 2020

Published online: 18 August 2020

\section{References}

1. Koeze J, Keus F, Dieperink W, van der Horst ICC, Zijlstra JG, van Meurs M. Incidence, timing and outcome of AKI in critically ill patients varies with the definition used and the addition of urine output criteria. BMC Nephrol. 2017;18:70.

2. Hoste EAJ, Bagshaw SM, Bellomo R, Cely CM, Colman R, Cruz DN, et al. Epidemiology of acute kidney injury in critically ill patients: the multinational AKI-EPI study. Intensive Care Med. 2015;41:1411-23.

3. Luo $X$, Jiang $L$, Du B, Wen $Y$, Wang $M, X i$ X, et al. A comparison of different diagnostic criteria of acute kidney injury in critically ill patients. Crit Care (London, England). 2014;18(4):R144.

4. Silver SA, Chertow GM. The economic consequences of acute kidney injury. Nephron. 2017:137(4):297-301.

5. Kerr M, Bedford M, Matthews B, O'Donoghue D. The economic impact of acute kidney injury in England. Nephrol Dial Transplant. 2014;29(7):1362-8.

6. Kellum JA, Lameire N, Group KAGW. Diagnosis, evaluation, and management of acute kidney injury: a KDIGO summary (Part 1). Crit Care. 2013;17(1):204.

7. Melo FAF, Macedo E, Fonseca Bezerra AC, Melo WAL, Mehta RL, Burdmann EA, et al. A systematic review and meta-analysis of acute kidney injury in the intensive care units of developed and developing countries. PLoS One. 2020;15(1):e0226325

8. Liang KV, Sileanu FE, Clermont G, Murugan R, Pike F, Palevsky PM, et al. Modality of RRT and recovery of kidney function after AKI in patients surviving to hospital discharge. Clin J Am Soc Nephrol. 2016;11(1):30-8.

9. Shum HP, Chan KC, Tam CW, Yan WW, Chan TM. Impact of renal replacement therapy on survival in patients with KDIGO stage 3 acute kidney injury: a propensity score matched analysis. Nephrology (Carlton). 2017.

10. Boltansky A, Bassa C, Melani S, Sepúlveda A, Maldonado I, Postigo J, et al. Incidence and consequences of acute kidney injury among patients admitted to critical care units. Revista Medica De Chile. 2015;143:1114-20.

11. Penuelas O, Muriel A, Frutos-Vivar F, Fan E, Raymondos K, Rios F, et al. Prediction and outcome of intensive care unit-acquired paresis. J Intensive Care Med. 2018;33:16-28.

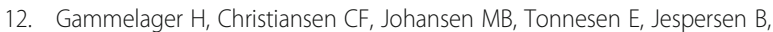
Sorensen HT. One-year mortality among Danish intensive care patients with acute kidney injury: a cohort study. Crit Care (London, England). 2012;16(4): R124.

13. Singh TB, Rathore SS, Choudhury TA, Shukla VK, Singh DK, Prakash J. Hospital-acquired acute kidney injury in medical, surgical, and intensive care unit: a comparative study. Indian J Nephrol. 2013;23(1):24-9.

14. Rimes-Stigare C, Frumento P, Bottai M, Martensson J, Martling CR, Walther $\mathrm{SM}$, et al. Evolution of chronic renal impairment and long-term mortality after de novo acute kidney injury in the critically ill; a Swedish multi-centre cohort study. Crit Care (London, England). 2015;19:221.

15. Cruz DN, Bolgan I, Perazella MA, Bonello M, de Cal M, Corradi V, et al. North East Italian Prospective Hospital Renal Outcome Survey on Acute Kidney Injury (NEiPHROS-AKI): targeting the problem with the RIFLE Criteria. Clin J Am Soc Nephrol. 2007;2(3):418-25.

16. Vanmassenhove J, Lameire N, Dhondt A, Vanholder R, Van Biesen W. Prognostic robustness of serum creatinine based AKI definitions in patients with sepsis: a prospective cohort study. BMC Nephrol. 2015;16:112.

17. Sigurdsson MI, Vesteinsdottir 1O, Sigvaldason K, Helgadottir S, Indridason OS, Sigurdsson $\mathrm{GH}$. Acute kidney injury in intensive care units according to RIFLE classification: a population-based study. Acta Anaesthesiol Scand. 2012;56(10):1291-7.

18. Banda J, Chenga N, Nambaya S, Bulaya T, Siziya S. Predictors of acute kidney injury and mortality in intensive care unit at a teaching tertiary hospital_ID. Indian J Crit Care Med. 2020;24(2):116-21.

19. Austin PC. An introduction to propensity score methods for reducing the effects of confounding in observational studies. Multivar Behav Res. 2011;46: 399-424. 
20. Austin PC. Balance diagnostics for comparing the distribution of baseline covariates between treatment groups in propensity-score matched samples. Stat Med. 2009;28(25):3083-107.

21. Cole SR, Hernan MA. Constructing inverse probability weights for marginal structural models. Am J Epidemiol. 2008;168(6):656-64.

22. Charlson ME, Pompei P, Ales KL, Mackenzie CR. A new method of classifying prognostic comorbidity in longitudinal studies: development and validation. J Chronic Dis. 1987:40(5):373-83.

23. Austin PC. Optimal caliper widths for propensity-score matching when estimating differences in means and differences in proportions in observational studies. Pharm Stat. 2011;10(2):150-61.

24. Yu R, Rosenbaum PR. Directional penalties for optimal matching in observational studies. Biometrics. 2019;75(4):1380-90.

25. Rubin DB, Thomas N. Matching using estimated propensity scores: relating theory to practice. Biometrics. 1996:52(1):249-64

26. Abudayyeh A, Song J, Abdelrahim M, Dahbour I, Page VD, Zhou S, et al. Renal replacement therapy in patients with stage IV cancer admitted to the intensive care unit with acute kidney injury at a comprehensive cancer center was not associated with survival. Am J Hosp Palliat Care. 2020; 1049909120902115.

27. Teles F, Santos RO, Lima H, Campos RP, Teixeira EC, Alves ACA, et al. The impact of dialysis on critically ill elderly patients with acute kidney injury: an analysis by propensity score matching. J Bras Nefrol. 2019;41(1):14-21.

28. Lebiedz P, Knickel L, Engelbertz C, Luders F, Gebauer K, Berdel WE, et al. Impact of preexisting chronic kidney disease on acute and long-term outcome of critically ill patients on a medical intensive care unit. J Nephrol. 2014;27(1):73-80

29. Schneeweiss S, Rassen JA, Glynn RJ, Avorn J, Mogun H, Brookhart MA. Highdimensional propensity score adjustment in studies of treatment effects using health care claims data. Epidemiology. 2009;20(4):512-22.

30. Stuart EA. Developing practical recommendations for the use of propensity scores: discussion of 'A critical appraisal of propensity score matching in the medical literature between 1996 and 2003' by Peter Austin, Statistics in Medicine. Stat Med. 2008;27(12):2062-5 discussion 6-9.

31. Day AG. Why the propensity for propensity scores? Crit Care Med. 2015 43(9):2024-6.

32. Hernan MA. A definition of causal effect for epidemiological research. J Epidemiol Community Health. 2004;58(4):265-71.

33. Chen Y, Feng F, Li M, Chang X, Wei B, Dong C. Development of a risk stratification-based model for prediction of acute kidney injury in critically ill patients. Medicine (Baltimore). 2019;98(33):e16867.

34. Malhotra R, Kashani KB, Macedo E, Kim J, Bouchard J, Wynn S, et al. A risk prediction score for acute kidney injury in the intensive care unit. Nephrol Dial Transplant. 2017:32(5):814-22.

\section{Publisher's Note}

Springer Nature remains neutral with regard to jurisdictional claims in published maps and institutional affiliations.

Ready to submit your research? Choose BMC and benefit from:

- fast, convenient online submission

- thorough peer review by experienced researchers in your field

- rapid publication on acceptance

- support for research data, including large and complex data types

- gold Open Access which fosters wider collaboration and increased citations

- maximum visibility for your research: over $100 \mathrm{M}$ website views per year

At $\mathrm{BMC}$, research is always in progress.

Learn more biomedcentral.com/submissions 